\title{
Long term soft tissue response to metals, ceramics and composites-a comparative histopathological evaluation
}

\author{
MIRA MOHANTY†, K RATHINAM* and C C KARTHA** \\ Divisions of Pathophysiology, *Toxicological Screening of Materials, BMT Wing, \\ ***athology, Sree Chitra Tirunal Institute for Medical Sciences and Technology, \\ Trivandrum 695012, India \\ MS received 2 July 1987: revised 10 October 1987
}

\begin{abstract}
Soft tissue reaction to metals, ceramics and composites was investigated over a long period. Titanium, nitrided titanium, ruby, sapphire and carbon-carbon composite materials were used. Histological response was uniform for all materials despite their differung chemical and physical properties.
\end{abstract}

Keywords. Soft tissue reaction; metals; composites; ceramics; long term evaluation: brocompatibility.

\section{Introduction}

In recent years, there has been great progress in the development of prosthetic devices for implantation. Metals, ceramics and lately composites have found wide applications in surgery. Among metals, the excellent corrosion resistance and good strength of titanium has proved it to be very useful as an orthopaedic implant. Ceramics have been tested and applied clinically in humans as prosthesis in orthopaedics and dentistry. Currently, sapphire is being tested as disc material in artificial heart valves with nitrided titanium as cage material. Carbon-carbon composite finds wide application as orthotic devices, artificial limbs, tendon replacements, dental and maxillofacial implants. Considering a variety of future clinical applications, a comparative long-term study of these materials seemed to be of importance. In this paper a long term histological study of tissue reaction to five different materials, possessing different chemical and physical properties, is being presented.

\section{Materials and methods}

The materials investigated were titanium, nitrided titanium, sapphire, ruby and carbon-carbon composite. All materials were of uniform shape of $10 \mathrm{~mm} \times 1 \mathrm{~mm}$ rods. The implants were sterilized by autoclaving prior to surgery and all surgical procedures were performed under general anaesthesia and under sterile conditions. Two rods of each material were implanted at different sites, in the paravertebral muscle of one side, with negative controls (proved non-toxic) in the contra-lateral side of rabbits.

The animals were observed closely for any acute post-surgical inflammatory respunse during the first 2 weeks of post-implantation period. At specific time intervals, the animals were sacrificed by exanguination. The implants were retrieved with surrounding tissue of approximately $2 \mathrm{~cm}$ thickness on all sides and were immedia-

$\dagger$ To whom all correspondence should be addressed 
tely placed in 10\% buffered neutral formalin for fixation. The next day, each implant was removed carefully from the muscle and a gross examination of the implant as well as the site of implantation was made. Thick pieces $(1 \mathrm{~mm})$ of muscle all around the implant site were processed by the conventional method for paraffin embedding. Thin sections stained with haematoxylin and eosin were examined by light microscopy. The histological response was evaluated according to the scoring method of Turner et al (1973).

\section{Results}

\subsection{Gross observations}

No acute post-surgical inflammatory reaction was observed in any animal. All implants at the end of 7 days were freely movable and not attached to the underlying muscle. The surface of all implants was smooth and the site of implantation showed a neat edge in the muscle. The implants and the surrounding muscle at the end of 6 weeks and 12 weeks showed a similar picture except in the case of carbon-carbon composite showing black discoloration of adjacent muscle, at the end of 6 months. All implants except titanium wire had a soft white material adherent to the surface. It was difficult to remove ruby, sapphire and nitrided titanium from the muscle after a year.

\subsection{Microscopic observations}

For most part the microscopic observations of the materials tested were uniform (table 1). At 7 days, there was moderate to marked necrosis of the skeletal muscle, with accompanying chronic inflammation (figure 1). Macrophages, lymphocytes and giant cells formed the cellular infiltrate. Repair was evident in the periphery by the

Table 1. 7 days post-implantation, histopathological evaiuation of adjacent muscle.

\begin{tabular}{lccccc}
\hline Histopathology & Titanium & $\begin{array}{c}\text { Nitrided } \\
\text { titanium }\end{array}$ & Sapphire & Ruby & $\begin{array}{c}\text { Carbon- } \\
\text { carbon } \\
\text { composite }\end{array}$ \\
\hline Muscle necrosis & $2+$ & $2+$ & $3+$ & $3+$ & $2+$ \\
Giant cells & $2+$ & $1+$ & $3+$ & $1+$ & $2+$ \\
Lymphocytes & $1+$ & 0 & $2+$ & $1+$ & 0 \\
Neutrophils & 0 & 0 & 0 & 0 & 0 \\
Eosinophils & 0 & 0 & 0 & 0 & 0 \\
Macrophages & $2+$ & $1+$ & $3+$ & $1+$ & $1+$ \\
Foreign body debris & $1+$ & $1+$ & 0 & 0 & $1+$ \\
Fibroblasts & $3+$ & $3+$ & $2+$ & $3+$ & $3+$ \\
Fibrosis & $1+$ & 0 & $1+$ & $2+$ & 0 \\
Fatty change & \pm & \pm & 0 & 0 & 0 \\
Haemorrhage & $1+$ & 0 & \pm & 0 & \pm \\
Oedema & 0 & 0 & 0 & 0 & 0 \\
\hline
\end{tabular}

Scoring: Based on a 0 to $3+$ scale; $0=$ item not present; $\pm=$ item occasionally present; $+=$ item present to a mild degree; $2+=$ item present to a moderate degree; $3+=$ item present to a marked degree. 

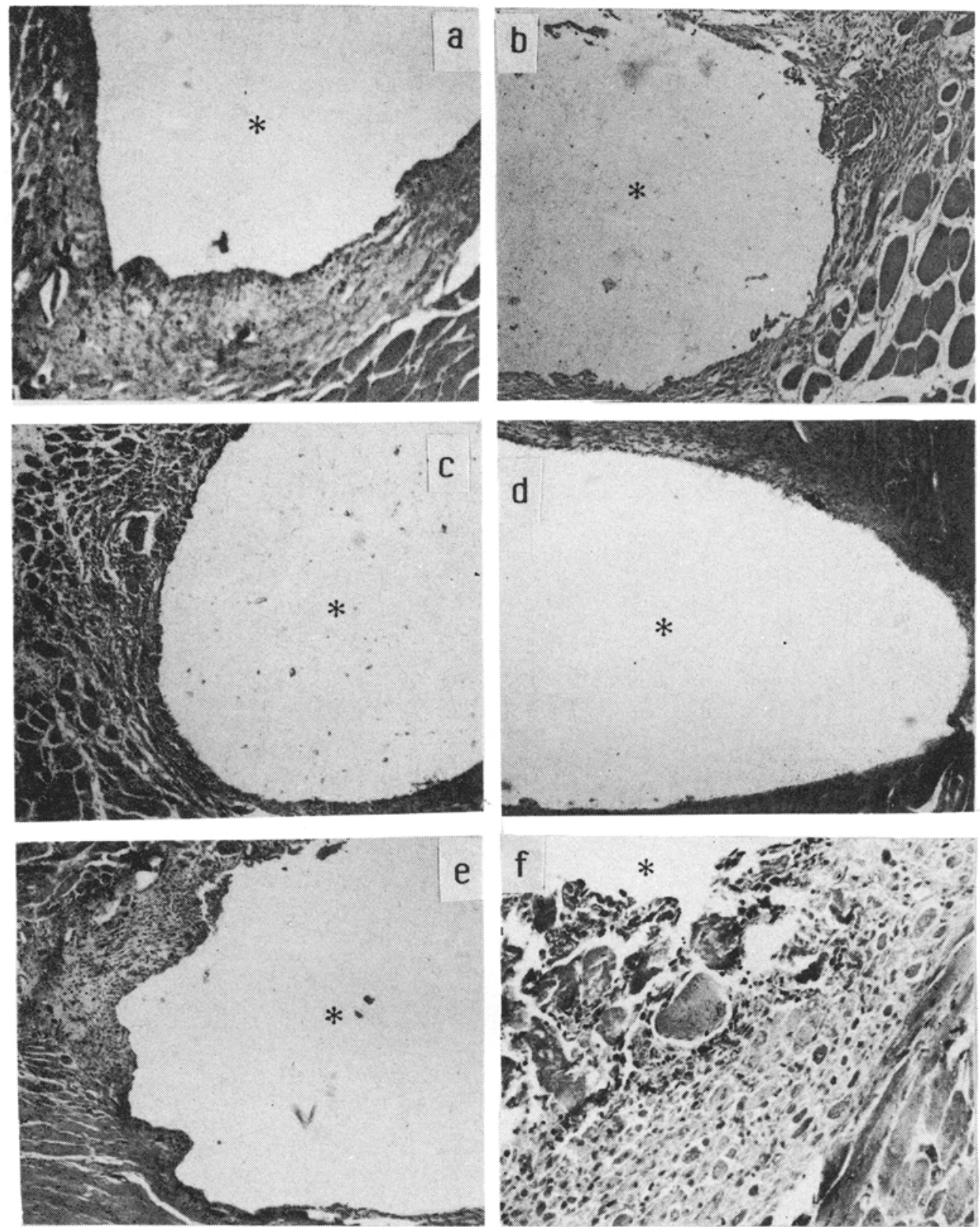

Figure 1. Light micruscopic picture of tissue reaction around implants at 7 days $(\times 60)$. a. Titanium, b. Nitrided titanium, c. Sapphire, d. Ruby, e. Carbon-carbon composite and $f$. Higher magnification of tissue around titanium showing necrotic fragments of muscle and inflammatory cells $(\times 150)$.

presence of immature fibroblasts and a few mature fibrocytes. Comparatively, the reaction to sapphire was of a higher degree.

By 6 weeks, the inflammation had cleared up. A capsule consisting of mature collagen with a few fibrocytes was seen surrounding all implants (figure 2). No 

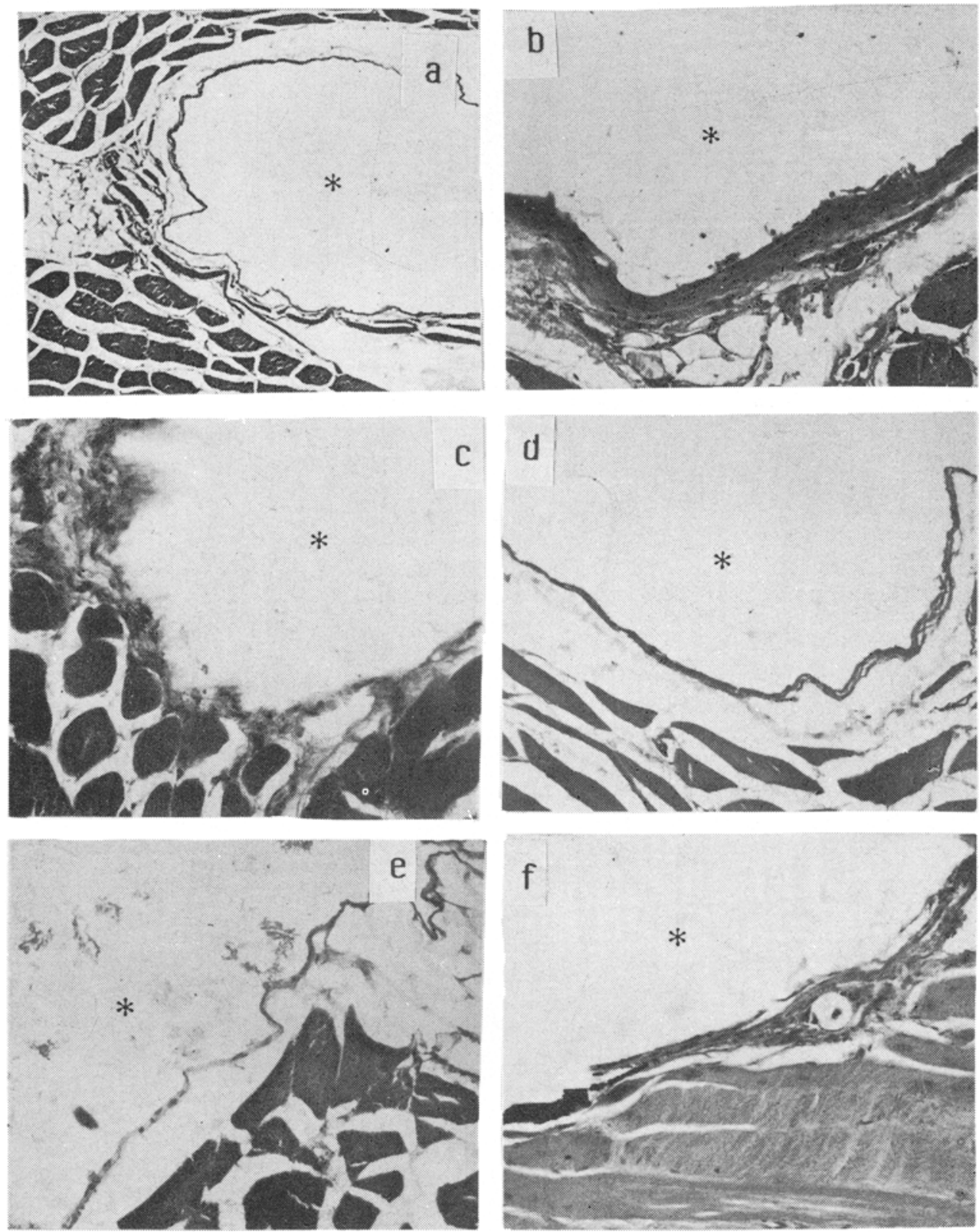

Figure 2. Photomicrograph of implant site at 6 weeks post implantation showing thin fibrous capsule $(\times 150)$. a. Low magnification picture of capsule around titanium $(\times 60)$, b. Titanium, c. Nitrided titanium, d. Sapphire, e. Ruby and f. Carboncarbon composite.

inflammatory cells were noted. The fibrous tissue adjacent to nitrided titanium and carbon-carbon composites was reduced to thin fibrils of collagen at certain places, having been separated off the surface of the implants.

The capsule decreased in thickness with time, till finally a very thin strip of com- 
pressed collagen remained surrounding the nitrided titanium, ruby and sapphire at 1 year (figure 3). At all time intervals, particles of titanium and carbon were seen scattered in adjacent soft tissue (figure 4). These were golden yellow and black titanium and black carbon particles. At no time during this study, there was any evidence of tumours adjacent to the implants.

\section{Discussion}

The purpose of this study was to investigate the biological response of soft tissue to long term implantation of metals, ceramics and composite materials. Semi-quantitative histopathological evaluations were used to describe the tissue reactions.

The ideal biocompatible material for the construction of surgical prosthesis should not be toxic, allergic or carcinogenic. Nor should it cause any local inflammation, but should at most cause a thin encapsulation of the process. The response of inflammation, followed by repair, noted at 7 days, 6 weeks and 12 weeks in all implants, was due to the irritation and presence of a foreign body, rather than any toxic influence upon the surrounding soft tissuc. The general histological trend of decreasing capsule thickness is typical of a reaction to a biologically acceptable material (Laing et al 1967). A similar observation has been made in the present study where there has been a failure to elicit any long term inflammation.

A soft white material was noted on the surface of implants at 6 months. This material resembles the layer or amorphous substance known to separate cells and extracellular fibrillar material from the surface of the implant (Albrektsson et al 1982). While removing the implant from the muscle, the adhesion between the two is
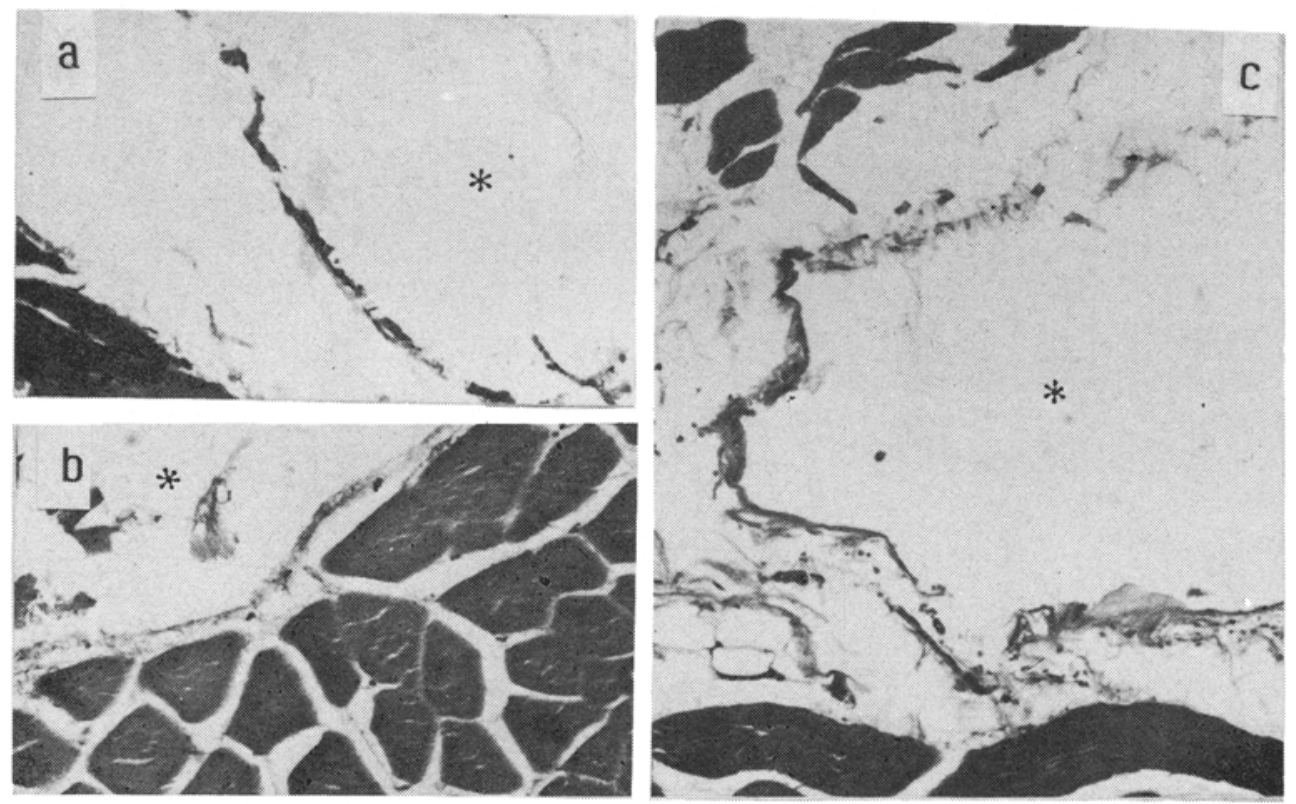

Figure 3. Photomicrograph of implant site at one year post-implantation $(\times 150)$. a. Nitrided titanium, b. Sapphire and c. Ruby. 


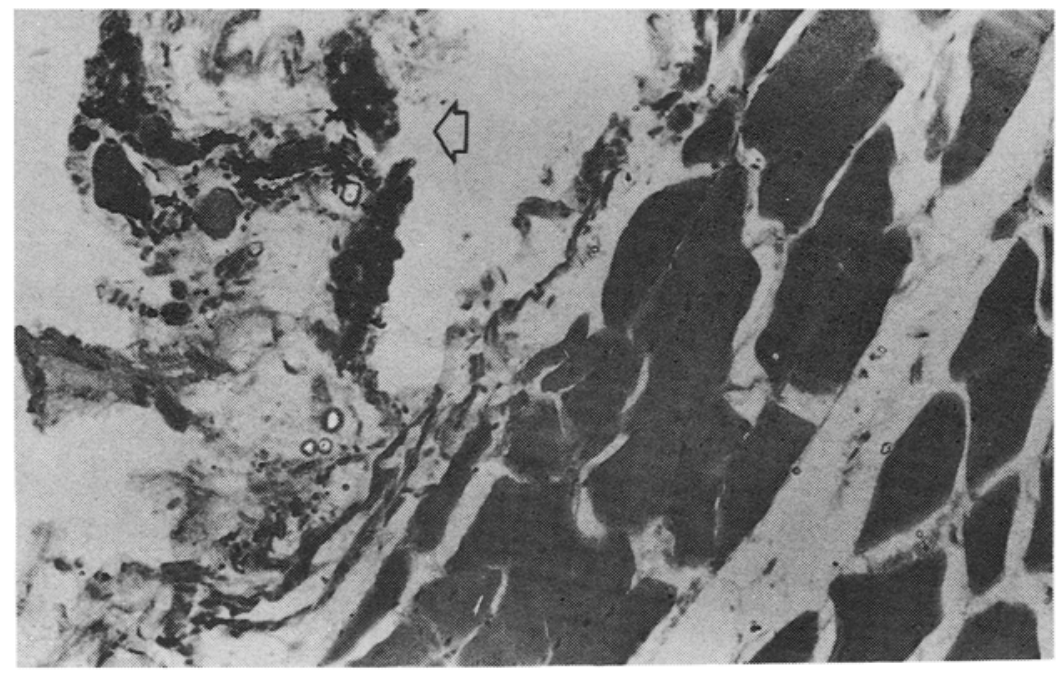

Figure 4. Photumicrograph of black carbon particles at the site of carbon-carbon composite implant, 6 months post-implantation $(\times 150)$.

broken and fine collagen fibrils (remnants of the bond) are seen in the histological sections. This type of adhesion may not be useful either in load-bearing situations or in mechanical stress, but it may be desirable in other applications such as replacement of ossicular chain and its transmucosal applications (Hench and Wilson 1984). It has been noted in this study that nitrided titanium forms a bond with adjacent tissue quite early at 6 weeks and may be termed as a type 3 biomaterial which is surface-reactive (Hench and Ethridge 1982). When this material is used as a rigid housing in heart valves (Chitra Heart Valve) the valve is anchored firmly to the surrounding cardiac tissue within a short time, thus improving the interfacial stability.

Increased amounts of titanium have been found in nonosseous tissue adjacent to the titanium implants in man and in rabbits (Meachim and Williams 1973). Though particles of titanium and carbon were found in tissues adjacent to the implanted area in the present study there was no evidence of toxic reaction around them. A notable feature was the absence of debri of sapphire, which makes it a good material for various intravascular biomaterial applications.

Though ceramics are strong and extremely hard, they have not been applied much for use in prosthetic devices. Brittleness and loss of strength in saline as well as when implanted in soft tissue have led to a conservative approach (Lynch 1982). However, in this study the soft tissue response to ceramics has been excellent over one year.

To conclude, our present study confirms the uniform tissue tolerance (biocompatibility) to the implanted metals, ceramics and composites in paravertebral muscle of rabbits.

\section{References}

Albrektsson T, Bramemark P I, Hansson H A, Ivarsson B and Jonsson U 1982 Adv. Biomater, 4167 Hench L L and Ethridge E C 1982 in Biomaterials - an interfacial approach (New York, London: Academic Press) Chapter 1, p. 3 
Hench L L. and Wilson J 1984 Science 226630

Laing P. Ferguson A and Hodge E 1967 J. Biomed. Mater. Res. 1135

Lynch W 1982 in Implants. Reconstructing the human body (New York: Van Nostrand) Chapter 1, p. 18 Meachim G and Williams D F 1973 J. Biomed. Mater. Res. 7555

Turner J E, Laurence W H and Autian J 1973 J. Biomed. Mater. Res. 739 